\title{
Procedimiento disciplinario en materia de empleo público en la provincia de Buenos Aires $^{1}$
}

Disciplinary procedure in matters of public employment in the province of Buenos Aires

Procedimento disciplinar em matéria de emprego público na província de Buenos Aires

Procédure disciplinaire en matière d'emploi public dans la province de Buenos Aires

Pablo Octavio Cabral ${ }^{2}$ Universidad Nacional de La Plata

Revista Derechos en Acción / ISSN 2525-1678 / e-ISSN 2525-1686

Año 4/No 10 Verano 2018/2019 (21 diciembre a 21 marzo), 78-109

DOI: https://doi.org/10.24215/25251678e246

ORCID: https://orcid.org/0000-0001-5768-4958

Recibido: 17/12/2018

Aprobado: 01/02/2019

Resumen: Se abordan los procedimientos administrativos disciplinarios que se desarrollan en el ámbito de la relación de empleo público en territorio bonaerense. Estos procedimientos especiales, conocidos como sumarios administrativos que tramitan ante la propia Administración empleadora, tienen por finalidad precisar todas las circunstancias y reunir los elementos de prueba tendientes a esclarecer la comisión de irregularidades -faltas administrativas-, individualizar a los agentes responsables y proponer y aplicar sanciones. Para realizar un estudio debemos contar con un plexo normativo y para ello abordaremos el régimen provincial de empleo público regulado en la ley № 10.430 -arts.80 a 106- y su reglamentación (Decreto 4161/96).

1 El presente texto se redactó con base en lo expuesto en los capítulos VII y VIII de la obra; Cabral, Pablo Octavio y Schreginger, Marcelo José; El régimen de Empleo Público en la Provincia de Buenos Aires, Abeledo Perrot, Buenos Aires, 2009.

2 Docente de Derecho Administrativo II, pablooctaviocabral@yahoo.com.ar. 
Palabras claves: Empleo público. Procedimiento administrativo. Potestad disciplinaria.

Abstract: The disciplinary administrative procedures that are developed within the scope of the public employment relationship in Buenos Aires territory are addressed. These special procedures, known as administrative summaries that are processed before the Employer Administration itself, are intended to specify all the circumstances and gather evidence to clarify the commission of irregularities-administrative bureaucracy-to identify the responsible agents and propose and apply sanctions To carry out a study we must have a normative plexus and for that we will address the provincial regime of public employment regulated by Law No. 10,430 -arts.80 to 106- (hereinafter LEP) and its regulations (Decree 4161/96).

Keywords: Public employment. Administrative Procedure. Disciplinary authority

Resumo: Serão abordados os procedimentos administrativos disciplinares que são desenvolvidos no âmbito da relação de emprego público no território de Buenos Aires. Esses procedimentos especiais, conhecidos como sumários administrativos que são processados na própria Administração empregadora, destinam-se a especificar todas as circunstâncias e reunir provas para esclarecer a comissão de irregularidades - faltas administrativas -, identificar os agentes responsáveis e propor e aplicar sanções Para realizar um estudo, devemos ter um plexo normativo e para isso vamos abordar o regime provincial de emprego público regulamentado na lei $\mathrm{N}^{0} 10.430$ - artigos 80 a 106 - (em diante LEP) e sua regulamentação (Decreto 4161/96).

Palavras-chave: Emprego público. Procedimento administrativo. Autoridade disciplinar.

Résumé: Dans cet article, il est question des procédures administratives disciplinaires appliquées dans le domaine des emplois publics sur le territoire de la province de Buenos Aires. Ces procédures spéciales, connues sous l'appellation d'instructions administratives, qui sont appliquées face à la propre administration employeur, ont pour objet de préciser toutes les circonstances et de rassembler les éléments de preuve visant à éclairer la commission des irrégularités - de fautes administratives - d'identifier les agents responsables et de proposer et 
appliquer des sanctions. Pour réaliser une étude, nous devons disposer d'un plexus normatif et, pour cela, nous aborderons le régime provincial de la fonction publique régi par la loi n ${ }^{\circ} 10430$-arts.80 à 106- (ci-après le LEP) et sa règlementation (décret 4161/96).

Mot-clés: Emploi public. Procédure administrative. Pouvoir disciplinaire.

\section{Introducción}

En el presente documento abordaremos los procedimientos administrativos disciplinarios que se desarrollan en el ámbito de la relación de empleo público en territorio bonaerense. Estos procedimientos especiales, conocidos como sumarios administrativos que tramitan ante la propia Administración empleadora, tienen por finalidad precisar todas las circunstancias y reunir los elementos de prueba tendientes a esclarecer la comisión de irregularidades -faltas administrativas-, individualizar a los agentes responsables y proponer y aplicar sanciones.

Para realizar un estudio debemos contar con un plexo normativo y para ello abordaremos el régimen provincial de empleo público regulado en la ley $\mathrm{N}^{\circ} 10.430$-arts.80 a 106- (en adelante LEP) y su reglamentación (Decreto 4161/96), dejando fuera la regulación normativa nacional, otros regímenes provinciales (docentes, policías, agentes penitenciarios, etc.), así como la legislación aplicable a los empleados públicos municipales (Ley 14.656, arts. 23 a 44).

\section{Contextualización. Conceptos y principios jurídicos aplicables}

El procedimiento administrativo disciplinario está alcanzado por diferentes ordenamientos jurídicos con normas y principios propios que deben intervenir para regular los sumarios administrativos en forma equilibrada (derecho administrativo, derecho laboral, derecho penal, derechos humanos). De un 
lado está el Estado, con su poder público que se manifiesta a través de la potestad sancionatoria (en el contexto de la relación laboral) y, en el otro una persona que presta servicios para la administración pública, con sus respectivos derechos como trabajador público (estabilidad propia, principios protectorios del trabajador, derechos laborales) y sus derechos a un debido procedimiento adjetivo (garantías procesales reconocidas constitucionalmente), en tanto ciudadano sometidos al poder punitivo de las autoridades públicas.

Explica Hutchinson que el procedimiento sancionador genérico tiene una doble finalidad, reparadora y sancionatoria, y que ejercita la potestad de la Administración de penar las extralimitaciones que cometan sus funcionarios y los particulares. Busca averiguar la realidad y extensión de la extralimitación cometida, ponderar las circunstancias que en ella concurren y aplicar las sanciones pertinentes. A partir de esta facultad sancionatoria el profesor distingue aquellos procedimientos que se incoan contra particulares -Correctivos- de los que se inician contra los propios funcionarios públicos cuando violan sus deberes -disciplinarios-. Aquí abordaremos estos últimos ${ }^{3}$.

El procedimiento sumarial en materia disciplinaria constituye herramienta administrativa (integrada por una sucesión de actos materialmente administrativos casualmente relacionados entre sí) para decidir y fundamentar una sanción a un agente $\mathrm{y}$, al mismo tiempo, es un carril formal que garantiza el derecho de defensa del propio trabajador estatal, ya que tiene por objeto habilitar la sanción, previa acreditación de hechos u omisiones que pudieren constituir faltas punibles y de todas sus circunstancias. Es por ello un instrumento jurídico que satisface el interés de la Administración pública (y a través de ella, el interés público), garantizando al mismo tiempo los derechos fundamentales de los trabadores estatales. 3 Hutchinson, Tomás: Procedimiento administrativo de la provincia de Buenos Aires, Astrea,
Buenos Aires, 1995. 


\section{II.1. La potestad sancionatoria}

El Estado cuenta para poder cumplir con sus funciones constitucionales y legales con prerrogativas que le permiten desarrollarlas plenamente, llamadas potestades, que no son otra cosa que facultades de actuación nacidas como consecuencia de habilitaciones del propio ordenamiento jurídico. Un ejemplo de ellas es la potestad sancionatoria o disciplinaria.

La facultad -en general- que la Administración tiene de aplicar sanciones a los administrados, deriva de su potestad sancionatoria, otorgada esta por el ordenamiento jurídico al Estado, en tanto se trata del titular del monopolio legal de la fuerza. La potestad es una manifestación del concepto genérico de poder jurídico, atribuido por el ordenamiento en forma previa e independiente de toda relación jurídica concreta.

Esta potestad sancionadora que posee el Estado puede ser ejercida por el Poder Ejecutivo, en aplicación de penas administrativas y por el Poder Judicial en cuanto éste sentencie a los ciudadanos por violación del ordenamiento jurídico. El procedimiento disciplinario discurre en el ámbito administrativo y es ejercido por la autoridad pública hacia el interior de su estructura organizativa.

El incumplimiento por parte de los agentes estatales de los deberes y prohibiciones derivados de la relación de empleo público genera consecuencias jurídicas de carácter sancionatorio que imponen obligaciones de reparar o satisfacer el daño causado. Dentro de la responsabilidad de los agentes estatales puede distinguirse las siguientes esferas, especies o categorías:

a) Responsabilidad civil, tendiente a reparar los daños de naturaleza patrimonial ocasionados a terceros por la actuación u omisión, tanto lícita como ilícita, del Estado. ${ }^{4}$

4 Es necesario aclarar que la responsabilidad del agente puede ser independiente, concomitante o derivada de la responsabilidad del Estado cuando el deber de responder sea externo, es decir, hacia terceros afectados por el actuar administrativo. Este tipo de responsabilidad, en la esfera nacional, se encuentra regulada legislativamente en la Ley 
b) Responsabilidad penal, que tiene por objeto punir a aquellos agentes que como autores, cómplices o instigadores incurrieren en delitos previstos en el Código Penal y sus leyes especiales, cuando su calidad de funcionario público determine o agrave la aplicación de la figura penal infringida.

c) Responsabilidad politica, sólo puede recaer en determinados funcionarios de alto rango por motivos previstos en la Constitución y tiene por finalidad -por un lado- su remoción y -además- quitar cierta inmunidad permitiendo su enjuiciamiento por delitos cometidos o por los daños que hubiere ocasionado.

d) Responsabilidad administrativa es la que nace frente a las irregularidades cometidas por quienes administran o custodian bienes y se tramita mediante los denominados juicios de cuentas (interviene el Tribunal de Cuentas de la Provincia de Bs. As. y se evalúa la rendición obligatoria que realizan funcionarios que administran dinero público provincial o municipal) y juicios de responsabilidad (interviene el Tribunal de Cuentas y la Contaduría General de la Provincia y procede cuando existe daño al erario público, tanto por culpa como por dolo del agente).

e) Responsabilidad disciplinaria, que procede en el ámbito interno de la organización y es propia y relativa a la relación de empleo público y puede comprender conductas realizadas tanto dentro como fuera del servicio, cuando han sido previstas por la ley, como las lesivas de la imagen o del buen funcionamiento del servicio. Dicha responsabilidad tiene por objeto inmediato proteger el buen funcionamiento

de Responsabilidad del Estado Nacional (№ 26.944) en su artículo 9 que dispone: "La actividad o inactividad de los funcionarios y agentes públicos en el ejercicio de sus funciones por no cumplir sino de una manera irregular, incurriendo en culpa o dolo, las obligaciones legales que les están impuestas, los hace responsables de los daños que causen. La pretensión resarcitoria contra funcionarios y agentes públicos prescribe a los tres (3) años. La acción de repetición del Estado contra los funcionarios o agentes causantes del daño prescribe a los tres (3) años de la sentencia firme que estableció la indemnización". 
de la Administración Pública, pero como fin trascendente, la necesaria satisfacción del bien público por parte del Estado.

Corresponde destacar que estas distintas modalidades de responsabilizar a los agentes estatales no se excluyen entres sí, pudiendo acumularse, sin por ello violentar el principio non bis in idem, con fundamento en que en cada una de las esferas se protegen bienes jurídicos independientes.

\section{II.2. La relación de empleo público, la estabilidad y los principios protectorios de los trabajadores}

Según la doctrina mayoritaria, el derecho disciplinario administrativo tiene por objeto sancionar aquellas conductas del agente público que lesionan el buen funcionamiento de la Administración Pública y que se originan en la inobservancia de los deberes inherentes a su calidad de agente público o en la comisión de acciones expresamente prohibidas por la normativa aplicable.

Por tratarse del ejercicio de una potestad estatal en el marco de una relación especial de trabajo, es necesario realizar una revisión de los conceptos centrales de la vinculación laboral conocida como empleo público.

La relación de empleo público puede ser definida como aquel contrato administrativo mediante el cual una persona física se compromete a la realización de una serie de tareas, previamente reglamentadas, por las cuales el Estado asume el pago de una suma de dinero en forma periódica, y con un conjunto más amplios de derechos. La relación discurre entre derechos, deberes, obligaciones y potestades públicas, regidos todos ellos por el derecho público. ${ }^{5}$

El trabajador del Estado, al igual que la persona que trabaja en el sector privado, se encuentra alcanzado por los principios

5 Ampliar en Cabral, Pablo Octavio y Schreginger, Marcelo José; El Régimen de Empleo Público en la Provincia de Buenos Aires, Editorial Abeledo Perrot, Buenos Aires, 2009", Cápituo II, Naturaleza jurídica y principios de la relación de empleo público. 
protectorios que se originaron en el Derecho laboral y que hoy se encuentran- en su mayoría- incorporados al bloque de constitucionalidad (art. 14 bis $\mathrm{CN}$ y tratados de derechos humanos). Un lugar especial en el abanico de derechos reconocidos a los agentes públicos lo ocupa la Estabilidad en el cargo. La Constitución Nacional dispone expresamente que las leyes aseguraran la estabilidad del empleado público (Art. 14 bis) y la Carta provincial establece que la carrera administrativa deberá ser legislado con base en la estabilidad del trabajador estatal (Art. 103, inc. 12 Const. Pcial.).

El paradigma que está presente en la doctrina administrativista más clásica es la primacía del Estado por sobre los particulares y la efectiva presencia del real poder estatal en sus relaciones con los ciudadanos, fundado en la superioridad del interés público por sobre los intereses individuales.

Esta desigualdad que inclina la balanza hacia el poder estatal también está presente en la relación del Estado con sus empleados. Los poderes y las prerrogativas del Estado, como defensor del interés general, deben primar, según esta concepción, por sobre los intereses particulares de los trabajadores que se desempeñan dentro de su órbita.

La paulatina incorporación de los derechos sindicales a los trabajadores estatales, junto con la constitucionalidad de los derechos sociales fundamentales, puso de relieva la contradicción entre los intereses sectoriales de los empleados públicos y esta concepción administrativista de la relación jurídica que los une con el Estado empleador y que sostiene que el empleo público satisface las necesidades colectivas por lo que, al organizarlo el Estado con fines de interés público justifica desconocer muchos derechos de los trabajadores públicos.

Entiendo que esto no es así, ya que de una correcta hermenéutica jurídica no se desprende tal oposición, sino por el contrario, existe una armonía que permite la coexistencia pacífica de las prerrogativas estatales, el interés público y los principios constitucionales y legales protectorios del derecho laboral. 


\section{II.3. Garantías procesales}

El procedimiento administrativo, entendido como la sucesión legalmente ordenada de hechos y actos, tendientes al nacimiento de una decisión final materialmente administrativa, se encuentra alcanzado en nuestro país por las garantías constitucionales de debido proceso, tutela procesal efectiva. El procedimiento disciplinario aplicable a la relación de empleo público provincial también se encuentra amparado por dichas garantías.

Así, el procedimiento disciplinario tiene como límite el derecho a la tutela judicial efectiva, postulado que irrumpió con toda su fuerza no sólo el ámbito judicial, sino también en el del procedimiento administrativo -como garantía de tutela efectiva-

Constitucionalmente a nivel nacional surge dicha protección del preámbulo de la Carta nacional ("afianzar la justicia") y de las garantías del debido proceso y defensa en juicio de su artículo 18. El gran cambio normativo se produjo con la incorporación de los Tratados Internacionales de protección de derechos humanos efectuada en el artículo 75, inciso 55 de la Constitución Nacional.

Concretamente ha sido muy importante el impacto derivado de la aplicación de los artículo 8 y 25 de la Convención Americana de Derechos Humanos por parte de la Corte Interamericana con sede en San José de Costa Rica, y la posterior recepción en nuestra sede nacional por un criterio interpretativo de la Corte Suprema de Justicia de la Nación ${ }^{6}$, seguido por los tribunales inferiores del ámbito federal y de las provincias ${ }^{7}$.

Con fecha 3 de mayo de 2016 la Corte Interamericana de Derechos Humanos dictó Sentencia en el caso Maldonado Ordoñez Vs. Guatemala, sometiendo un procedimiento

\footnotetext{
6 CSJN, Causa "Giroldi", sent. de 7-IV-1995.

7 Por ejemplo, la SCBA interpretó la garantía del debido proceso legal de acuerdo con los criterios interpretativos de la Corte Interamericana de Derechos Humanos. SCBA, causa B. 56.626, "Suárez", sent. de 17-XII-2003; causa A.68.782, "Colegio de Bioquímicos de la PBA", sent. de 22-XII-2008.
} 
disciplinario -desarrollado en el marco de una relación de empleo público- al test de cumplimiento de las garantías del debido proceso establecidas en el artículo 8 de la Convención Americana de Derechos Humanos (CADH). Allí el Tribunal declaró responsable internacionalmente al Estado guatemalteco por la violación del: 1) derecho a conocer el fundamento de la acusación, contenido en el artículo 8.2.b de la Convención Americana; 2) derecho a la defensa, contenido en el artículo 8.2.c de la Convención Americana, y 3) deber de motivación y al principio de legalidad, contenidos en los artículos 8.1 y 9 de la Convención Americana.

Dijo la Corte que cualquier actuación u omisión de los órganos estatales dentro de un proceso, sea administrativo sancionatorio o jurisdiccional, debe respetar el debido proceso legal y que las garantías mínimas expresadas en el art. 8.2. de la $\mathrm{CADH}$ deben respetarse en el procedimiento administrativo $\mathrm{y}$ en cualquier otro procedimiento cuya decisión pueda afectar los derechos de las personas. Analizó el Tribunal el derecho del sumariado administrativamente a tener una comunicación previa y detallada de la acusación y derecho a la defensa, el deber de motivación y principio de legalidad

Recordó que el principio de presunción de inocencia constituye un fundamento de las garantías judiciales, y que dichas garantías deben observarse en los procedimientos en que se determinen o se afecten derechos y obligaciones de orden civil, laboral, fiscal o de cualquier otro carácter.

Finalmente, en relación al principio de legalidad, la reiteró que el artículo 9 de la $\mathrm{CADH}$ es aplicable a la materia sancionatoria administrativa, indicando que las sanciones administrativas son una expresión del poder punitivo del Estado y que tienen, en ocasiones, naturaleza similar a las sanciones penales. Unas y otras implican menoscabo, privación o alteración de los derechos de las personas, como consecuencia de una conducta ilícita. Por lo tanto, en un sistema democrático es preciso extremar las precauciones para que dichas medidas 
se adopten con estricto respeto a los derechos básicos de las personas y previa una cuidadosa verificación de la efectiva existencia de la conducta ilícita. Asimismo, en aras de la seguridad jurídica es indispensable que la norma sancionatoria exista y resulte conocida, o pueda serlo, antes de que ocurran la acción o la omisión que la contravienen y que se pretende sancionar. En concordancia con lo anterior, la Corte considera que el principio de legalidad también tiene vigencia en materia disciplinaria, no obstante su alcance depende considerablemente de la materia regulada. La precisión de una norma sancionatoria de naturaleza disciplinaria puede ser diferente a la requerida por el principio de legalidad en materia penal, por la naturaleza de los conflictos que cada una está destinada a resolver.

Este principio rector del procedimiento disciplinario se encuentra explicitado en el artículo 80 de la ley de empleo público -en adelante LEP- $^{8}$ que consagra la vigencia plena del principio nullum crimen sine lege previa respecto de los agentes de la Administración Pública provincial, ya que proscribe tanto la aplicación de sanciones disciplinarias como cualquier forma de extinción del vínculo por causas y procedimientos que no hayan sido determinados por la ley general de empleo público y su reglamentación.

El principio de legalidad, como vimos consagrado expresamente en la ley de empleo público, exige:

a) La atribución legal de la potestad disciplinaria;

b) La determinación de los tipos sancionables;

c) La determinación de las sanciones aplicables.

Esta consagración legislativa impide la apreciación como faltas de conductas que no hayan sido impuestas previamente

8 Art. 80 de la ley 10.430: "Los agentes de la Administración Pública de la Provincia no podrán ser objeto de sanciones disciplinarias ni privados de su empleo, sino por las causas y procedimientos determinados en esta ley y su reglamentación. Art. 80, Decreto 4161/96: “La acción disciplinaria es el ejercicio del poder disciplinario que tiene la Administración Pública para sancionar a sus agentes por los hechos u omisiones que constituyan faltas administrativas" 
como deberes o prohibiciones, así como tampoco aplicar otras sanciones que las previstas por la ley. El respeto al principio de legalidad para aplicar las sanciones determinadas en la ley es riguroso, no pudiendo apartarse de las especies previstas en dicho principio.

\section{El procedimiento disciplinario en la provincia de Buenos Aries}

\section{III.1. Regulación constitucional y legal}

La SCBA sintetiza la constitucionalización de la relación de empleo público en nuestra provincia reconociendo ciertos principios o bases fundamentales que surgen del ordenamiento constitucional':

1- La estabilidad en el cargo (arts. 14 bis, CN; 103 inc. 12 Const. Pcial.).

2- El derecho a la carrera administrativa (art. 103 inc. 12 Const. Pcial).

3- La idoneidad para el acceso a la función (arts. 16 CN; 103, inc. 12 Const. Pcial.)

4- Régimen de incompatibilidades (arts. 53 y 103, inc. 12 Const. Pcial.)

5- Negociación colectiva (art. 39, inciso 4 Const. Pcial).

6- Respecto del Procedimiento Disciplinario; la tutela efectiva y el debido proceso frente al ejercicio de la potestad sancionatoria (arts. $18 \mathrm{CN}$ y 15 Const. Pcial)

Legalmente, el procedimiento disciplinario se encuentra regido por normas específicas dentro de la ley de empleo público - $\mathrm{N}^{\mathrm{o}}$ 10.430- (Régimen disciplinario, arts. 80 a 106 y su reglamentación por Decreto 4161/1996), que para aquellas cuestiones no normadas remite supletoriamente al decreto

9 SCBA, causa I 2021, "Municipalidad de San Isidro c/ Provincia de Buenos Aires s/ Inconstitucionalidad de ley 11.757", sent. de 27-VIII-2014. 
ley de procedimiento administrativo $-\mathrm{N}^{\circ} 7647 / 70-$ y a la ley procedimientos penales provincial.

\section{III.2. Presupuestos y sanciones disciplinarias}

\section{III.2.1. Presupuestos}

Los presupuestos para dar inicio a un procedimiento disciplinario en materia de empleo público es necesario que la Administración tome conocimiento respecto de: 1) la existencia de una falta administrativa, 2) que sea imputable al agente o empleado y 3) que su actuar sea culposo o doloso. Además, es exigencia legal que el poder disciplinario no se encuentre extinguido por fallecimiento del responsable, desvinculación del agente o prescripción (4).

\section{1) Falta administrativa}

El principal presupuesto, como se pudo observar al desarrollar el principio de legalidad, es la presunta existencia de una falta administrativa, entendida como todo acto $u$ omisión del funcionario, que viole deberes funcionales. Como lo dice expresamente la reglamentación del artículo 80 de la LEP, la acción disciplinaria es el ejercicio del poder disciplinario que tiene la Administración Pública para sancionar a sus agentes por los hechos u omisiones que constituyan faltas administrativas.

La falta disciplinaria es el presupuesto de hecho necesario para aplicar la sanción, ya que la configuración de la falta determina la posibilidad de actuar o ejercer la potestad disciplinaria; en consecuencia, para hacer efectiva la sanción, el agente necesariamente tiene que haber cometido una falta.

La falta siempre consiste en una violación de un deber o prohibición legítimamente impuesto, éste puede ser relativo a la función o constituir una conducta exigida fuera de sus funciones por ser considerada negativa para el funcionamiento de la Administración. 


\section{2) Imputación}

La conducta -tanto activa como omisiva- debe ser atribuible en su autoría al agente que será imputado en el procedimiento disciplinario como realizador de la falta administrativa prevista en la norma aplicable.

\section{3) Culpa o dolo}

La posibilidad de sancionar a un trabajador estatal exige que la conducta que se le atribuye haya sido adoptada con culpa o dolo.

Podemos acercarnos conceptualmente a la culpa entendiéndola como la omisión de aquellas diligencias o acciones, positivas o negativas, que exigiere la naturaleza de la obligación y que correspondiesen a las circunstancias de las personas, del tiempo y del lugar, ya para dar cumplimiento a un comportamiento debido, ya para prever o evitar un daño (arts. 512, Cód. Civil -hoy derogado- y 1724, Código Civil y Comercial).

El dolo, por su parte, supone la intención de conseguir el resultado reprochado por el ordenamiento jurídico manifestado en la conducta del autor que persigue el resultado previsto en la prohibición. La legislación civil regula el dolo como vicio de la voluntad, entendiendo que acción dolosa es toda aserción de lo falso o disimulación de lo verdadero, cualquier artificio, astucia o maquinación que se emplee para la celebración del acto. La omisión dolosa causa los mismos efectos que la acción dolosa, cuando el acto no se habría realizado sin la reticencia u ocultación (arts. 931 y 933, Cód. Civil -hoy derogado- y 271, Código Civil y Comercial).

\section{4) Extinción del poder disciplinario de la Administración}

La potestad disciplinaria en materia sancionatoria debe estar presente como exigencia previa al inicio y sustanciación del procedimiento sumarial.

Tal facultad se extingue, según lo dispone expresamente la LEP en sus artículos 90 y 91 ante: 
a) El fallecimiento del responsable.

b) La desvinculación del agente con la administración, salvo que la sanción pueda modificar las causas del cese.

c) La prescripción (1 año para sanciones correctivas y 3 años para sanciones expulsivas).

d) Si la falta constituye delito, el plazo de prescripción de la acción disciplinaria será la establecida en el código penal.

La ley delega en la reglamentación el establecimiento de las causales de interrupción y suspensión de la prescripción. ${ }^{10}$

\section{III.2.2. Sanciones disciplinarias}

Las sanciones disciplinarias, en tanto consecuencia jurídica o castigo por haber cometido una falta, tienen como finalidad prevenir o reprimir las conductas violatorias de los deberes y prohibiciones que han sido impuestos para procurar el normal funcionamiento de la Administración o para proteger el interés público que a ella se le ha encomendad, coincidiendo en ello con la finalidad de la potestad disciplinaria por ser la consumación de ésta.

Las sanciones pueden son clasificadas en la $\operatorname{LEP}^{11}$ de la siguiente forma:

1- Sanciones correctivas (apercibimiento y suspensión): Son de tipo preventivo: Son de tipo preventivo y tienen por objeto advertir al agente en forma expresa o implícita del

\footnotetext{
10 Artículo 91 Decreto 4161/96: “I. La comisión de una nueva falta, la orden de instrucción del sumario y los actos de procedimientos disciplinarios que tiendan a mantener el movimiento la acción disciplinaria, interrumpen el plazo de la prescripción de la misma. También lo interrumpen las acciones presumariales. II. El proceso judicial suspende el término de la prescripción hasta su resolución definitiva y siempre que de las actuaciones administrativas no surja probada responsabilidad disciplinaria, en cuyo caso podrá dictarse resolución final, dejando establecido que la misma queda subordinada al resultado de aquél. III. El plazo de la prescripción corre, se suspende o se interrumpe separadamente para cada uno de los responsables de la falta."

11 Artículo 81 Ley 10.430: "Se aplicarán, en los casos que corresponda, sanciones disciplinarias de orden correctivo o expulsivo, las que a su vez respectivamente, podrán implicar apercibimiento o suspensión hasta SESENTA (60) días corridos y cesantía o exoneración."
} 
riesgo de recibir una sanción más grave frente a un nuevo incumplimiento.

2- Sanciones expulsivas (cesantía y exoneración): Se caracterizan por extinguir la relación laboral.

\section{III.2.3. Deberes, prohibiciones y causales de sanciones}

En el capítulo dedicado al régimen disciplinario, la LEP identifica las causales que habilitan, por un lado, la aplicación de una sanción correctiva, y por el otro los que facultan a la imposición de una sanción expulsiva, ya sea cesantía o exoneración. Veamos:

El artículo 82 indica las causales de las sanciones de apercibimiento y suspensión:

Artículo 82.- Serán causales para aplicar sanciones de carácter correctivo, las siguientes:

a) Incumplimiento reiterado del horario fijado por las leyes y reglamentos.

b) Inasistencias injustificadas que no excedan de diez días discontinuos en el lapso de doce meses inmediatos anteriores y siempre que no configuren abandono de servicio. La reglamentación podrá determinar los términos, forma y condiciones de las sanciones que correspondan al agente que incurra en inasistencias sin justificar.

c) Falta de respeto a los superiores, iguales, subordinados o al público.

d) Negligencia en el cumplimiento de sus tareas o funciones.

e) Incumplimiento de los deberes determinados en el artículo 78 o quebrantamiento de las prohibiciones establecidas en el artículo 79, salvo que por su magnitud y gravedad deban ser encuadradas bajo las figuras de cesantía o exoneración.

El artículo 83 hace lo propio con la sanción de cesantía:

Artículo 83.- Serán causales para aplicar cesantías, las siguientes: 
a) Abandono del servicio sin causa justificada.

b) Faltas reiteradas en el cumplimiento de sus tareas o falta grave respecto a los superiores, iguales, subordinados o al público.

c) Inconducta notoria.

d) Incumplimiento de las obligaciones determinadas en el artículo 78 o quebrantamiento de las prohibiciones determinadas en el artículo 79 cuando a juicio de la autoridad administrativa por la magnitud y gravedad de la falta así correspondiera.

e) Incumplimiento intencional de órdenes legal y fehacientemente impartidas.

f) Inasistencias injustificadas reiteradas que excedan de diez días discontinuos, en los doce meses inmediatos anteriores.

g) Concurso civil o quiebra no causal, salvo caso debidamente justificado por la autoridad administrativa.

Finalmente, en el artículo 84 de explicitan las causales correspondientes a la sanción más gravosa:

Artículo 84.- Son causas de exoneración:

a) Falta grave que perjudique material o éticamente a la Administración.

b) Sentencia condenatoria dictada contra el agente como autor, cómplice o encubridor por delito contra la administración o delito grave de carácter doloso de acuerdo al Código Penal.

c) Las previstas en las leyes especiales.

d) Pérdida de la nacionalidad, conforme a las leyes que reglan la materia.

e) Imposición de pena principal o accesoria de inhabilitación absoluta o especial para la función pública.

Como surge de los textos normativos transcriptos, las sanciones correctivas y la cesantía están atadas al incumplimiento de los deberes previstos en el artículo 78 y al quebrantamiento de las prohibiciones establecidas en el artículo 79 de la LEP. 
El deber jurídico puede ser conceptualizado como la imposición de una conducta -positiva o negativa-, fundada en razones de interés público, derivada de una norma habilitante, de un contrato o de un acto administrativo. Constituyen deberes de los agentes públicos cuando se establezcan como consecuencia de la relación de empleo público.

Así, en su artículo 78 la LEP dispone como deberes de los trabajadores estatales de la provincia: prestación de servicios, obediencia, reserva, guardar secreto, cuidado del patrimonio estatal, comportamiento correcto dentro y fuera del trabajo, atención correcta a los administrados, mantenimiento de buen trato con los compañeros, conocimiento de las normas que lo rigen, capacitación, denunciar irregularidades administrativas que lleguen a su conocimiento, mantener un compromiso democrático, declarar su patrimonio, excusarse, declarar actividades laborales, declarar domicilio real, declarar en sumarios administrativos y respetar la vía jerárquica, sin perjuicio de lo que particularmente impongan las leyes, derechos, resolución y disposiciones. ${ }^{12}$

\footnotetext{
12 Artículo 78: "Deberes. Sin perjuicio de lo que particularmente impongan las leyes, decretos, resoluciones y disposiciones, los agentes deben cumplir estricta e ineludiblemente las siguientes obligaciones: a) Prestar servicios en forma regular y continua, dentro del horario general, especial o extraordinario que de acuerdo a la naturaleza y necesidad de los mismos se determine, con toda su capacidad, dedicación, contracción al trabajo y diligencia, conducentes a su mejor desempeño y a la eficiencia de la Administración Pública. b) Obedecer las órdenes de un superior jerárquico con jurisdicción y competencia cuando éstas se refieran al servicio y por actos del mismo y respondan a las determinaciones de la legislación y reglamentación vigentes. Cuestionada una orden dada por el superior jerárquico, advertirá por escrito al mismo sobre toda posible infracción que pueda acarrear su cumplimiento. Si el superior insiste por escrito, la orden se cumplirá. c) Mantener, en todo momento, la debida reserva que los asuntos del servicio requieren de acuerdo a la índole de los temas tratados. d) Cuidar los bienes del Estado, velando por la economía del material y la conservación de los elementos que fueran confiados a su custodia, utilización y examen. e) Observar, en el servicio y fuera de él, una conducta decorosa y digna, acorde con las tareas que le fueran asignadas. f) Proceder con cortesía, diligencia y ecuanimidad en el trato con el público. g) Mantener vínculos cordiales, demostrar espíritu de cooperación, solidaridad y respeto para con los demás agentes de la Administración. h) Conocer fehacientemente las reglamentaciones, disposiciones y todas aquellas normas que hacen a la operatividad y gestión de la Administración y las referidas específicamente a las tareas que desempeña. i) Cumplir los cursos de capacitación, perfeccionamiento y exámenes de competencia que se dispongan con la finalidad de mejorar el servicio. j) Dar cuenta, por la
} 
Por su parte, las prohibiciones son las omisiones o abstenciones impuestas por el ordenamiento jurídico al trabajador en su relación laboral, que -a diferencia de los deberes-, tienen en general finalidad preventiva, ya sea para evitar caer en incompatibilidades $\mathrm{o}$, directamente, para neutralizar conductas perjudiciales para la Administración.

El artículo 79 de la LEP establece las siguientes prohibiciones a los agentes públicos provinciales; incurrir en incompatibilidades en el ejercicio de su cargo, percibir beneficios económicos no autorizados, excederse intencionalmente en su competencia, tener vínculos contractuales en forma directa o indirecta, mantener vínculos patrimoniales con contratistas estatales o fiscalizados por su dependencia, expresarse en forma negativa respecto de las autoridades administrativas o de sus actos, utilizar bienes o servicios del Estado en su provecho, practicar la usura, circular o promover suscripciones o donaciones, ejercer actividades comerciales dentro del ámbito de la Administración Pública, promover o aceptar homenajes, actuar como gestor o patrocinante en el ámbito administrativo o judicial de tareas a su cargo, realizar gestiones inherentes a la relación de empleo fuera del canal jerárquico, usar indebidamente su credencial, exigir adhesiones políticas, religiosas o sindicales a otros agentes y hacer abandono de sus tareas. ${ }^{13}$

\footnotetext{
vía jerárquica correspondiente a los organismos de fiscalización y control, de las irregularidades administrativas que llegaren a su conocimiento. k) Respetar las instituciones constitucionales del país, sus símbolos, su historia y sus próceres. I) Declarar bajo juramento, en la forma y tiempo que la ley respectiva y su reglamentación establezcan, los bienes que posea y toda alteración de su patrimonio. m) Excusarse de intervenir en todo aquello en que su actuación pueda originar interpretación de parcialidad. n) Declarar bajo juramento los cargos y/o actividades oficiales o privadas, computables para la jubilación, que desempeñe o haya desempeñado, como asimismo toda otra actividad lucrativa. o) Declarar y mantener actualizado su domicilio ante la repartición donde presta servicios, el que subsistirá a todos los efectos legales mientras no denuncie otro nuevo. p) Declarar en los sumarios administrativos ordenados por autoridad competente, siempre que no tuviere impedimento legal para hacerlo, así como también en las informaciones sumarias. q) Observar la vía jerárquica en toda presentación referida a actos de servicio y mientras no se hubiere dispuesto otro procedimiento".
}

13 Artículo 79 "Prohibiciones. Está prohibido a todo agente, complementariamente a lo que dispongan otras normas y reglamentaciones: a) Percibir estipendios o recompensas que 
Un lugar especial ocupa en la ley las inasistencias al trabajo, pues establece en su artículo 85 que para aquellas faltas a cumplir sus labores que se encuentren injustificadas se disponen sanciones que van de los cinco días de suspensión hasta la cesantía. El caso más gravoso para el agente se constituye cuando incurre en tres inasistencias consecutivas, sin previo aviso, pues con la previa intimación podrá ser considerado en abandono de cargo decretándose su cesantía sin substanciación de sumario. ${ }^{14}$

no sean los determinados por las normas vigentes, aceptar dádivas u obsequios que se ofrezcan como retribución de actos inherentes a sus funciones o como consecuencia de ellas. b) Arrogarse atribuciones que no le correspondan. c) Ser directa o indirectamente, proveedor o contratista habitual u ocasional de la Administración Pública o dependiente 0 asociado de las mismas. d) Asociarse, dirigir, administrar, asesorar, patrocinar o representar a personas físicas o jurídicas, que cuestionen o exploten concesiones o privilegios de la Administración Provincial, salvo que las mismas cumplan un fin social o de bien público y que no se manifiesten incompatibilidades entre las funciones o tareas asignadas en la Administración y las desarrolladas en tales entidades, ni puedan presumirse situaciones de favoritismo 0 arbitrariedad en el otorgamiento de tales beneficios, así como también, mantener relación de dependencia con entes directamente fiscalizados por la repartición a que pertenezca. e) Referirse en forma evidentemente despectiva por la prensa o por cualquier otro medio, a las autoridades 0 a los actos de ellas emanados, pudiendo, sin embargo, en trabajos firmados 0 de evidente autoría, criticarlos desde un punto de vista doctrinario o de la organización del servicio. f) Retirar y/o utilizar, con fines particulares, los bienes del Estado y los documentos de las reparticiones públicas, así como también los servicios del personal a su orden dentro del horario de trabajo que el mismo tenga fijado. g) Practicar la usura en cualquiera de sus formas. h) Hacer circular o promover listas de suscripciones o donaciones dentro de la repartición, salvo que las mismas cumplan un fin social, en cuyo caso deberá mediar la correspondiente autorización superior. i) Vender todo tipo de artículos o ejercer cualquier actividad comercial en el ámbito de la Administración Pública. j) Promover o aceptar homenajes y todo otro acto que implique sumisión u obsecuencia a los superiores jerárquicos. k) Patrocinar trámites 0 gestiones administrativas o judiciales referentes a asuntos de terceros que se encuentren o no oficialmente a su cargo. I) Realizar gestiones, por conducto de personas extrañas a las que jerárquicamente corresponda, en todo lo relacionado con los derechos y obligaciones establecidos en este régimen. m) Hacer uso de las credenciales otorgadas por el servicio para autenticar su calidad de agente público en forma indebida o para fines ajenos a sus funciones. n) Exigir adhesiones políticas, religiosas o sindicales a otros agentes en el desempeño de su función. o) Hacer abandono del servicio sin causa justificada."

14 Artículo 85: "El agente que incurriera en TRES (3) inasistencias consecutivas, sin previo aviso y previa intimación fehaciente será considerado incurso en abandono de cargo y se decretará su cesantía sin substanciación de sumario El agente que incurra en inasistencias sin justificar será sancionado conforme se indica seguidamente: a) Por tres inasistencias en 
Por último, el artículo 87 de la LEP dispone que el agente podrá ser sancionado disciplinariamente con suspensión de hasta diez días sin necesidad de instrumentar el procedimiento sumarial por funcionario no inferior a Director. En estos casos, previamente a la aplicación de la sanción, se hará saber al agente la falta cometida, la norma transgredida y el derecho a presentar descargo en el plazo de tres días.

\section{III.3. Inicio}

El sumario administrativo por el que tramita un procedimiento disciplinario en materia de empleo público, requiere el cumplimiento de los requisitos previos expuestos arriba, y que tal circunstancia sea comunicada a la Administración Pública mediante un carril formal.

Así, su promoción exige que la falta administrativa sea denunciada por la propia administración mediante alguno de sus agentes o por una denuncia fundada de alguna persona externa a dicha organización.

El primer caso se da cuando, como lo posibilita el artículo 92 de la LEP, es pedida la instrucción del sumario "por cualquiera de los titulares de una unidad orgánica aprobada”.

Para el segundo tipo de casos, en los que una persona realiza una denuncia fundada, la reglamentación dispone que las personas extrañas a la Administración podrán presentar

\footnotetext{
el término de hasta TRESCIENTOS SESENTA Y CINCO (365) días entre la primera y la tercera: CINCO (5) días de suspensión. b) Por tres inasistencias en el término de hasta TRESCIENTOS SESENTA Y CINCO (365) días entre la primera y la tercera registradas en un lapso de hasta DOS (2) años, a contar de la última que motivó la sanción del inciso anterior: QUINCE (15) días de suspensión. c) Por tres inasistencias en el término de hasta TRESCIENTOS SESENTA Y CINCO (365) días entre la primera y la tercera registradas en un lapso de hasta DOS (2) años a contar de la última que motivó la sanción del inciso anterior: TREINTA (30) días de suspensión. d) Por tres inasistencias en el término de hasta TRESCIENTOS SESENTA Y CINCO (365) días entre la primera y la tercera registradas en un lapso de hasta DOS (2) años a contar de la última que motivó la sanción del inciso anterior: Cesantía. Al agente que se halle en las faltas que prevén los incisos a), b), c) y d) se le otorgará CINCO (5) días para que formule descargo, previo a la resolución que deberá adoptar la autoridad que corresponda."
} 
denuncia oral o escrita ante la autoridad respectiva, la que tendrá la obligación de recibirla, sobre hechos u omisiones que puedan configurar faltas. El denunciante no será considerado parte de las actuaciones. En caso que la denuncia sea oral, se labrará acta, la que en lo esencial, deberá contener: lugar y fecha, identificación del denunciante acreditado con su documento de identidad, relación de los hechos denunciados, identificador de los agentes denunciados y los elementos de prueba, debiendo el acta ser firmada por el denunciante en presencia del funcionario interviniente y por éste último, entregándosele copia certificada.

Si se tratare de denuncia efectuada por escrito, se citará al denunciante para que dentro de los tres días, ante el titular de la repartición en que se hubiese cometido la presunta falta, o quien éste designe a tal efecto, ratifique el contenido de la misma y reconozca la firma que la suscribe, dejándose constancia de lo actuado en acta con las formalidades de la última parte del apartado anterior. No lográndose la comparencia del denunciante y no siendo posible establecer la autenticidad de la firma, se decretará el archivo de las actuaciones. El mismo procedimiento se seguirá cuando la denuncia proceda de fuente anónima, fuere formulada bajo firma apócrifa o cuando la denuncia hubiera sido retractada.

\section{III.4. Desarrollo}

Establece la reglamentación que, para el caso de una denuncia de persona externa a la administración, presentada una denuncia y cumplidos los requisitos precedentes, el funcionario que la reciba la elevará de inmediato a la autoridad superior de la dependencia, si no hubiere sido radicada directamente ante la misma, y ésta deberá practicar las diligencias preventivas necesarias, dando oportuna intervención al órgano administrativo competente.

Luego procede el traslado de la denuncia al agente denunciado. En oportunidad de efectuarse el traslado al agente de la 
falta cometida, de acuerdo a lo dispuesto en el primer párrafo del artículo 87 de la Ley, deberá indicarse con precisión el hecho que se le atribuye, detallando las circunstancias de tiempo y lugar de su producción.

\section{III.4.1. Sustanciación ante la Dirección Provincial de Sumarios}

Establece la reglamentación que la dependencia con competencia específica para conocer en las causas previstas en el artículo 92 de la Ley es la Dirección de Sumarios, cuyo titular tiene las siguientes facultades: a) La organización de la Dirección proponiendo, la creación de los organismos internos que estime adecuados para el cumplimiento de sus funciones. b) Designar el o los instructores que sustanciarán los sumarios y los secretarios letrados, si correspondiere. c) Resolver las cuestiones de procedimientos que se sustanciaren durante la tramitación de los sumarios. d) Requerir directamente a todas las reparticiones provinciales y/o municipales los informes que considere indispensables, sin necesidad de seguir la vía jerárquica. Los organismos provinciales deberán evacuar los informes requeridos dentro de los cinco días. e) Elevar a la Junta de Disciplina, previo dictamen, las actuaciones sumariales para la prosecución de su trámite.

\section{III.4.2. Orden de sumario}

El procedimiento disciplinario toma el primer impulso procedimental con la emisión de la orden de sumario, que consiste en el acto $\mathrm{u}$ orden que dispone la instrucción de dicho procedimiento y la que deber contener "ineludiblemente", en forma clara y precisa: la mención de los hechos a investigar y la individualización del agente involucrado. Es irrecurrible y debe notificarse siempre que hubiere un agente individualizado. Junto con la orden se debe remitir a la Dirección de Sumarios, el legajo personal del denunciado, su último domicilio y un informe de concepto de su superior inmediato. 


\section{III.4.3. Instrucción del sumario y prueba de cargo}

La instrucción del sumario será llevada a cabo por medio del instructor - quienes deberán revistar preferentemente en categoría igual o superior a la del agente sumariado y tendrán título universitario de Abogado, Escribano o Procurador- que al efecto designe el Director de Sumarios, el que cumplirá su cometido de acuerdo al procedimiento que se establece en esta reglamentación y que no podrá superar el plazo de sesenta días (plazo fundadamente prorrogable por el Director de Sumarios).

El instructor deberá practicar todas aquellas diligencias conducentes a la acreditación de los hechos y omisiones que constituyan faltas administrativas y de todas sus circunstancias, para determinar la culpabilidad o inocencia del o de los sumariados. Tanto los instructores como sus secretarios son recusables por las causas dispuestas en la reglamentación del artículo 92 de la LEP y se encuentran obligados a excusarse ante la presencia de una de ellas. ${ }^{15}$

El sumario será secreto hasta que el instructor dé por finalizada la prueba de cargo y las actuaciones del sumario deberán realizarse por escrito, utilizándose preferentemente la escritura a máquina. De todas las diligencias que se practiquen se levantará

\footnotetext{
15 Artículo 92, Decreto 4161/96; “...XVII. El sumariado podrá recusar al instructor por algunas de las siguientes causas: a) Parentesco por consanguinidad dentro del cuarto grado civil o segundo por afinidad con alguno de los involucrados o denunciantes. b) Ser o haber sido denunciado 0 acusado por un delito o falta disciplinaria por alguno de los involucrados o denunciantes. c) Ser o haber sido denunciador o acusador del que recusa. d) Tener interés directo 0 indirecto en el resultado del sumario, que se manifieste por parcialidad evidente en la investigación. e) Tener el instructor, su cónyuge 0 sus parientes consanguíneos hasta el cuarto grado 0 afines hasta el segundo, pleito pendiente con el recusante. f) La amistad íntima con alguno de los involucrados o denunciantes, que se manifieste por frecuencia en el trato. g) Enemistad manifiesta o resentimiento por hechos graves y conocidos con involucrados o denunciantes. h) Ser o haber sido tutor o curador de involucrados o denunciantes. i) Tener comunidad de intereses con involucrados o denunciantes. j) Ser acreedor, deudor 0 fiador de involucrados o denunciantes. k) Haber recibido el instructor de parte del imputado beneficio de importancia o después de iniciado el sumario, presentes o dádivas, aunque sean de poco valor. I) Las causales de recusación enunciadas precedentemente alcanzarán igualmente al representante o patrocinante del inculpado."
} 
acta o certificación, con indicación del lugar y fecha, la que será firmada por todas las personas que hayan intervenido en ella. El instructor deberá rubricar cada una de las hojas que utilice mediante su firma, juntamente con los intervinientes, y sellos correspondientes. En lo no previsto en materia de actuaciones, se aplicarán las disposiciones del Decreto-Ley $N^{\circ} 7647 / 70$ o la norma que lo reemplace.

La reglamentación del procedimiento sumarial regula la forma y modos de realizar las notificaciones, así como los medios de prueba. Sobre estos últimos el Decreto 4161/96 regula: 1. La declaración del Imputado; 2. La confesión; 3. La prueba testimonial; 4. El careo; 5. La prueba pericial; 6. La prueba documental; 7 . La prueba informativa y 8 . El reconocimiento.

Las decisiones de la instrucción en materia probatoria son irrecurribles. Para lo que no esté previsto en materia probatoria, serán de aplicación supletoria las normas del Código de Procedimiento Penal, en cuanto no se opongan a lo normado en dicha reglamentación.

III.4.4. Conclusión de la prueba de cargo, levantamiento del secreto y auto de imputación

Concluida la prueba de cargo, el instructor dispondrá el levantamiento del secreto del sumario. Si, a su juicio, se encontrare acreditada la comisión de falta administrativa e individualizado el o los autores, procederá a dictar auto de imputación, el que deberá contener en sus considerandos: a) La exposición metódica de los hechos, relacionándolos, con las pruebas agregadas al expediente. b) La participación que en ellos tuvieren cada uno de los imputados, mencionando claramente a los mismos, por sus nombres y apellidos completos. Las circunstancias atenuantes y agravantes, que puedan modificar la responsabilidad de los imputados, desde una base estrictamente probatoria, sin poder incurrir en valoraciones que vayan más allá de la comprobación o no de la existencia de la falta. 
En la parte dispositiva el auto de imputación contendrá: a) El encuadramiento legal que corresponda a los hechos relacionados y a la sanción disciplinaria que estime aplicable. b) El otorgamiento de traslado para descargo y ofrecimiento de prueba a los imputados.

No existiendo, a criterio del instructor, elementos de juicio suficientes para la prosecución de las actuaciones, propiciará el sobreseimiento, elevándolas al Director de Sumarios. El Director de Sumarios examinará las actuaciones y si compartiere el temperamento propuesto, las remitirá a la Junta de Disciplina con opinión fundada. Podrá asimismo disponer se dicte providencia de imputación, en cuyo caso deberá designar nuevo instructor en el mismo acto. También podrá disponer el dictado de nuevo auto de imputación, prosiguiéndose con el procedimiento establecido a partir del apartado siguiente.

\section{III.4.5. Traslado a los imputados. Descargo y prueba de parte y alegato}

Dictada la providencia de imputación, se dará vista de todo lo actuado al imputado por el término de diez días, dentro de los cuales deberá efectuar su descargo y proponer las medidas de prueba que crea oportunas para su defensa. Cuando haya más de un imputado, los términos serán independientes y comenzarán a correr a partir del día siguiente hábil en que cada uno se haya notificado de la vista.

En su escrito de descargo el inculpado deberá constituir domicilio en forma clara y precisa, el que se considerará subsistente para todos los efectos legales mientras no designe otro, no pudiendo constituirlo en oficinas públicas. Asimismo, deberá ofrecer la totalidad de la prueba que estime necesaria, la que se sustanciará de acuerdo con las formalidades establecidas para la investigación, en las normas de la presente reglamentación, cualquiera sea la denominación que le asigne el imputado.

Concluida la prueba de descargo, se correrá nuevo traslado de las actuaciones a cada imputado, para que alegue sobre el mérito de la producida dentro del término de cinco días. 


\section{III.4.6. Cierre del sumario}

El instructor procederá a decretar el cierre del sumario en las siguientes circunstancias: a) Cuando el imputado no hubiera presentado el descargo y se haya dado por decaído el ejercicio de ese derecho. b) Cuando presente descargo y no ofrezca prueba a producir. c) Cuando haya alegado sobre el mérito de la prueba de descargo o se le haya dado por decaído el ejercicio de ese derecho.

\section{III.5. Dictámenes. Junta de disciplina, Asesoría General de Gobierno y Fiscalía de Estado}

La LEP en su artículo 93 crea la Junta de Disciplina, única y permanente, otorgándole la competencia de organismo asesor de la administración pública en materia disciplinaria y cuyas funciones son: expedirse en los sumarios administrativos previamente al dictado de la resolución, aconsejando la sanción a aplicar si correspondiere, expedirse en los supuestos de solicitudes de rehabilitación y expedirse en los casos en que se requiera su intervención por la autoridad competente. Su integración la delega -mediante el art. 94- a la reglamentación, sólo reservando la obligación de incluir una representación gremial.

La ley en el siguiente artículo, dispone la intervención previa de la Asesoría General de Gobierno, cuando se trate de una falta que pueda dar lugar a la aplicación de una sanción expulsiva, y la intervención de la Fiscalía de Estado cuando de modo directo existan intereses fiscales afectados. Ambos organismos deberán expedirse en el plazo de diez días mediante la emisión de un dictamen, para lo cual, podrán recabar medidas ampliatorias.

\section{III.6. Resolución final}

Una vez pronunciada la autoridad sumariante, la Junta de Disciplina y, en su caso la Asesoría General de Gobierno y la Fiscalía de Estado, las actuaciones serán remitidas a la autoridad 
competente para que dicte la resolución definitiva con ajuste a lo establecido

La LEP establece en su artículo 88 que toda sanción deberá aplicarse por resolución fundada que contenga la clara exposición de los hechos y la indicación de las causas determinantes de la medida.

Resultan autoridades competentes para aplicar sanciones disciplinarias en el ámbito provincial:

a) El Poder Ejecutivo, las expulsivas.

b) Los Ministros, Secretarios, Subsecretarios, Directores Generales o Provinciales, y demás funcionarios con idéntico rango a los enumerados, las correctivas.

c) Los Directores, o sus equivalentes, las correctivas limitándose la suspensión hasta un máximo de diez días.

Especifica el artículo 100 de la LEP que el acto administrativo final deberá ser dictado dentro de los cinco días de recibidas las actuaciones y deberá resolver respecto del imputado/s:

a) Sancionarlo.

b) Absolverlo.

c) Sobreseerlo en el sumario.

d) Declarar extinguida la potestad disciplinaria de la Administración por alguna de las causales previstas.

\section{Impugnación en sede administrativa y judicial}

\section{1. Impugnación en sede administrativa. Vías recursivas}

La ley dispone como medio de impugnación del acto administrativo sancionador con el que culmina el sumario administrativo, dos recursos que actúan como remedios específicos para defender los derechos del trabajador estatal frente a la Administración empleadora.

El procedimiento disciplinario prevé la posibilidad que el agente impugne en la propia sede administrativa la decisión que dispuso aplicarle una sanción y para ello regula dos recursos a 
tal efecto; el recurso de revocatoria con jerárquico en subsidio (1) y el recurso de revisión (2).

El primero de ellos -revocatoria con jerárquico en subsidio- es el más común y lo establece la ley en su artículo 104 que contra los actos administrativos que impongan sanciones disciplinarias, el sancionado podrá interponer recurso de revocatoria, con el jerárquico en subsidio, ante el mismo organismo que lo dictó, dentro del término de los diez días siguientes al de su notificación. El recurso deberá fundarse, debiendo rechazarse el mismo sin más trámite si se omitiera tal requisito.

El segundo -revisión-, caracterizado como una impugnación de excepción, está legislado en su artículo 105 en el que dice que -en cualquier tiempo- el agente sancionado o de oficio, el Estado, podrá solicitar la revisión del sumario administrativo del que resultara pena disciplinaria, cuando se aduzcan hechos nuevos o circunstancias sobrevinientes susceptibles de justificar la inocencia del imputado. Cuando se trate de agentes fallecidos, la revisión podrá ser requerida por el cónyuge, descendientes, ascendientes, hermanos o la persona que comprobadamente hubiera convivido en calidad de cónyuge, o de oficio por la misma Administración. En todos los casos deberán acompañarse los documentos y pruebas en que se funda la revisión: en su defecto, ésta será desechada sin más trámite. Especifica que no constituyen fundamento para la revisión las simples alegaciones de injusticia de la sanción.

\section{2. Impugnación en sede judicial. El proceso contencioso administrativo bonaerense}

Establece la Constitución bonaerense en su artículo 166 que los casos originados por la actuación u omisión de la Provincia, los municipios, los entes descentralizados y otras personas, en el ejercicio de funciones administrativas, serán juzgados por tribunales competentes en los contencioso administrativo, de acuerdo a los procedimientos que determine la ley, la que establecerá los supuestos en que resulte obligatorio agotar la vía administrativa. 
Así, nuestro sistema judicial de revisión de la actuación y omisión de la Administración Pública provincial y municipal se estructura sobre el Fuero Contencioso Administrativo -integrante orgánico del Poder Judicial- y corre por el carril procesal legislado en el Código Contencioso Administrativo -CCA- (ley 12.008 y modificatorias).

En el inciso 1 del listado de los casos incluidos en el Artículo $2^{\circ}$ del CCA se dispone: "La competencia contencioso administrativa comprende las siguientes controversias: 1...Quedan incluidas en este inciso las impugnaciones [...] que se deduzcan en contra de actos sancionatorios dispuestos en el ejercicio de la policía administrativa- a excepción de aquéllas sujetas al control del órgano judicial previsto en los Artículos 166, segundo párrafo, 172 y 216 de la Constitución de la Provincia de Buenos Aires y 24 inciso 3) de la Ley No 11.922."

Las sanciones administrativas aplicadas en un procedimiento disciplinario en el marco de una relación de empleo público provincial o municipal pueden ser entonces impugnadas judicialmente ante el Fuero Contencioso Administrativo, con aplicación al trámite del CCA, pudiendo el agente podrá optar entre recurrir al proceso ordinario, apelando a una de las pretensiones dispuestas en el artículo 12 del CCA o utilizar el procedimiento especial de impugnación de sanciones en materia de empleo público regulado en sus artículos 71 a 73 .

En este último caso el código le otorga al trabajador público una opción por el proceso sumario, al decir que contra los actos administrativos que dispongan sanciones disciplinarias a los agentes públicos provinciales o municipales, la parte actora, en el escrito inicial, podrá optar por formular las pretensiones previstas en el artículo $12^{\circ}$ del presente Código, por la vía del proceso ordinario, o por la del sumario prevista en este Capítulo.

La particularidad de este proceso especial es la abreviación de los plazos de su procedimiento judicial, con la finalidad clara de simplificar el juicio y brindar una garantía eficaz a la hora de efectivizar derechos fundamentales defendidos por 
la parte más débil de la relación laboral. El plazo de caducidad previsto para interponer la demanda, que en el proceso ordinario es de noventa días, se reduce a sesenta debiendo computarse de igual forma que la prevista en el artículo 18 del CCA. ${ }^{16}$

En el artículo 73 del CCA $^{17}$ el legislador dejó expresamente regulado el contenido que debe tener toda sentencia que se dicte en sentido favorable al trabajador público que opta por transitar su juicio por este proceso especialmente previsto para la impugnación de sanciones. De esa forma refleja indirectamente aquellas cuestiones de fondo reguladas por el derecho administrativo como el sistema de nulidades, el contenido de las reparaciones y las medidas conducentes a cumplir con la decisión judicial.

Si bien en el primer punto se delimita con esmerada descripción el contenido de los fallos estimatorios de la demanda anulatoria, en su segundo acápite el artículo remite a los contenidos de las sentencias dictadas en el proceso ordinario previstos en el artículo 50 del propio código, ampliando expresamente la gama de medidas por las que pueden optar los magistrados.

Para el caso en que la sentencia resulte desfavorable al actor, el magistrado, en aplicación de los artículos 70 y 50 del

16 Artículo 72: (Texto Ley 13101) Plazo para la demanda. Reglas procesales. La pretensión deberá deducirse dentro de los sesenta (60) días contados en la forma prevista en el artículo 18 del presente Código. El trámite se regirá por las normas previstas en el Capítulo I del Título II del presente Código, con las siguientes excepciones: 1. Contestada la demanda, 0 vencido el plazo para hacerlo, no habiendo hechos controvertidos, el Juez declarará la cuestión de puro derecho y firme dicha providencia llamará autos para sentencia. 2. Si hubiere hechos controvertidos, en una misma providencia el Juez dispondrá la producción de las pruebas pertinentes.

17 Artículo 73.- (Texto según Ley 13101) SENTENCIA FAVORABLE. 1. Si la sentencia fuera favorable al impugnante, dispondrá conforme a las particularidades del caso todas 0 algunas de las siguientes medidas: a) La anulación total o parcial de la sanción. b) La reincorporación del agente, si la sanción hubiera sido expulsiva. c) El reconocimiento de los haberes devengados. 2. De acuerdo a las características de la causa cuando se anulare una sanción expulsiva, junto con la declaración de nulidad, el órgano jurisdiccional podrá ordenar la adopción de las medidas que estimare conducentes con arreglo a lo dispuesto en el artículo 50 del presente Código. 
CCA, deberá limitarse a desestimar la pretensión intentada por el trabajador estatal rechazando la demanda.

\section{Orientación bibliográfica}

El texto de la clase constituye una guía para el estudio que requiere necesariamente lecturas complementarias.

Material bibliográfico general sobre procedimiento administrativo:

Hutchinson, Tomás, Procedimiento administrativo de la provincia de Buenos Aires, Editorial Astrea, Buenos Aires, 1995.

Bibliografía específica sobre empleo público provincial:

Cabral, Pablo Octavio y Schreginger, Marcelo José; El régimen de Empleo Público en la Provincia de Buenos Aires, Editorial Abeledo Perrot, Buenos Aires 2009 (en especial, Capítulos VII y VIII).

Literatura específica referida al procedimiento administrativo disciplinario:

Repetto, Alfredo; Procedimiento administrativo disciplinario. El sumario. Editorial Cathedra Jurídica, Buenos Aires, Buenos Aires, 2008.

Maljar, Daniel; El derecho administrativo sancionador. Editorial Ad-Hoc, Buenos Aires, 2004.

Nieto, Alejandro; Derecho Administrativo Sancionador, Editorial Tecnos, Madrid, 2006. 